\title{
Seawater intrusion into coastal aquifers - a case study
}

\author{
J. Letha \& D. B. Krishnan \\ Civil Engineering Department, College of Engineering, \\ Trivandrum, India
}

\begin{abstract}
Seawater intrusion into coastal aquifers is a major problem in almost all parts of the world. The increasing demand for fresh water in coastal regions is being met by the coastal aquifers. The development and management of fresh groundwater resources in coastal aquifers are seriously constrained by the presence of seawater intrusion. For proper management of coastal aquifers, it is necessary to assess the extent of saltwater intrusion in the aquifers. In the present study a numerical model based on solute transport, which can simulate seawater intrusion, is studied and is applied to an actual field situation. The extent and pattern of seawater intrusion in the region is simulated under the present situation. Simulations are also carried out to find the effect of pumping rate on the intrusion pattern in the vertical direction. The model is applied to an actual field problem. The model is calibrated in steady state to estimate model parameters such as conductivity and specific yield. Simulation runs are performed for the model to calculate groundwater heads in the region for a period of 180 days. When these heads are compared with the observed heads it yields a correlation coefficient of 0.75 . The model is then calibrated in the transient state and when the transient heads are compared with observed heads a correlation coefficient of 0.98 is obtained. The model is then applied to simulate seawater intrusion in the horizontal direction. It is seen that the advancement of the seawater intrusion front is at maximum for a depth of $28-40 \mathrm{~m}$ from the ground surface. The simulation is also carried out to see the effect of the pumping rate on the advancement of the seawater intrusion front in the vertical direction in the region along the three pumping wells namely Karichal, Pollinkudi and Adimalathura. The rate of advancement in the intrusion front in the Pollinkodi pump well is found to be greater than the other pumping wells.

Keywords: seawater intrusion, coastal aquifers, seawater intrusion front, extent and pattern of seawater intrusion, variation with pumping rate.
\end{abstract}




\section{Introduction}

In coastal areas coastal aquifers prove to be an important source of groundwater resource. Under-utilization of the available water resources means that the valuable fresh water will discharge naturally into the sea and be wasted. Over exploitation of the groundwater resources causes degradation of water quality due to the encroachment of seawater. Hence the development and management of coastal groundwater aquifers is an important issue. When groundwater is pumped from the aquifer, the fresh water level is lowered and the sea intrudes into the aquifer. With excessive pumping, the natural hydraulic gradient towards the sea may be reversed and the intrusion may extend to the pumping borehole, making it saline. For proper management of coastal aquifers, it is necessary to assess the extent of saltwater intrusion in the aquifers.

\section{Objectives}

The present study aims at simulating seawater intrusion into coastal aquifers using already developed numerical code available from literature and to apply the same to a case study. Hence the following objectives are formulated:

1) To apply a numerical model based on the theory of groundwater flow and solute transport to simulate seawater intrusion.

2) To identify an actual field problem and collect field data pertaining to the problem that would serve as input information to the numerical model.

3) To idealize the problem so that the solute transport numerical model is conveniently fitted to the field situation.

4) To calibrate the model using the known groundwater heads and estimate the parameters like conductivity and specific yield.

5) To estimate the extent and pattern of seawater intrusion in the study region.

\section{Theoretical basis}

This section describes the flow equation and solute transport equation given by Langevin et al. [6] wherein both equations form the governing equation for the simulation of seawater intrusion.

\subsection{Mathematical model}

The form of the flow equation used in the model is as follows:

$$
\begin{aligned}
& \nabla\left[\rho K_{f}\left(\nabla h_{f}+\frac{\rho-\rho_{f}}{\rho_{f}} \nabla z\right)\right]= \\
& \rho S_{s f} \frac{\partial h_{f}}{\partial t}+n \frac{\partial \rho}{\partial C} \frac{\partial C}{\partial t}-\rho_{s} q_{s}^{\prime}
\end{aligned}
$$

where $K_{f}$ is the fresh water hydraulic conductivity tensor given by $K_{f}=k \rho_{f} g / \mu_{f}$ $\left[\mathrm{LT}^{-1}\right], \mathrm{n}$ is porosity $[-], \rho$ is fluid density $\left[\mathrm{ML}^{-3}\right], \mathrm{t}$ is time $[\mathrm{T}], \mathrm{q}$ is specific 
discharge $\left[\mathrm{LT}^{-1}\right]$, and q', is a source or sink $\left[\mathrm{T}^{-1}\right]$ of fluid with density $\rho_{\mathrm{s}}$. $\mathrm{k}$ is the permeability tensor $\left[\mathrm{L}^{2}\right], \mu$ is dynamic viscosity $\left[\mathrm{ML}^{-1} \mathrm{~T}^{-1}\right]$ and $\mathrm{hf}$ is fresh water head given by

$$
h_{f}=\frac{p}{\rho_{f} g}+z
$$

$\mathrm{p}$ is pressure $\left[\mathrm{ML}^{-1} \mathrm{~T}^{-2}\right], \mathrm{g}$ is gravity $\left[\mathrm{LT}^{-2}\right]$, and $\mathrm{z}$ is the upward coordinate direction.

$\mathrm{S}_{\mathrm{sf}}$ is the fresh water specific storage $\left[\mathrm{L}^{-1}\right]$ defined as the volume of water released from storage per unit volume per unit decline of fresh water head, and $\mathrm{C}$ is the concentration of solute mass per unit volume of fluid $\left[\mathrm{ML}^{-3}\right]$.

The general form of the solute transport equation is given as:

$$
\frac{\partial(n C)}{\partial t}=\nabla \cdot(n D . \nabla C)-\nabla \cdot(q C)-q_{s}^{\prime} C_{s}
$$

where $\mathrm{D}$ is the hydrodynamic dispersion coefficient tensor $\left[\mathrm{L}^{2} \mathrm{~T}^{-1}\right]$ and $\mathrm{C}_{\mathrm{s}}$ is the source or sink concentration $\left[\mathrm{ML}^{-3}\right]$.

\section{Methodology}

The flow and solute transport equations are numerically solved using software SEAWAT. The entire period of simulation is divided into different stress periods depending on the strength of source or sink $\left(q_{s}^{\prime}\right)$. Each stress period is further divided into one or more time steps to produce results more accurately. The length of time step is then calculated during the simulation by SEAWAT to satisfy the stability constraint given in (4)

$$
\Delta t=\frac{n}{q_{s}^{\prime}}
$$

Then the flow equation and solute transport equation are solved using the explicit method. With the explicit method, a lagged approach is used for assigning fluid densities in the flow equation. This means that fluid densities are calculated with solute concentrations from the previous time step. Advective flux from the flow solution for the current time step is then used to solve the transport equation in the current time step. This solute concentration is then used to update the fluid density. This updated fluid density is then used to solve flow equation for the next time step. This procedure is repeated until all the stress periods in the entire simulation are complete.

\section{Study area}

The study region lies in the Thiruvananthapuram district of Kerala. The coastal region stretches for about $78 \mathrm{~km}$ and has an elevation less than $8 \mathrm{~m}$ above mean sea level (MSL) parallel to the coast. Coastal alluvial soils as well as laterites cover the area parallel to the coast. The average rainfall is around $150 \mathrm{cms}$ per annum. The study region is a portion of the coastal region of 


\section{The Sustainable City V}

Thiruvananthapuram district from Vizinjam to Karichal and has a total area of 20 sq.km. Figure 2 shows the study region. In this area drinking water requirement is met from groundwater sources through bore wells constructed by the Kerala Water Authority. There are four bore wells and one open well in the region.

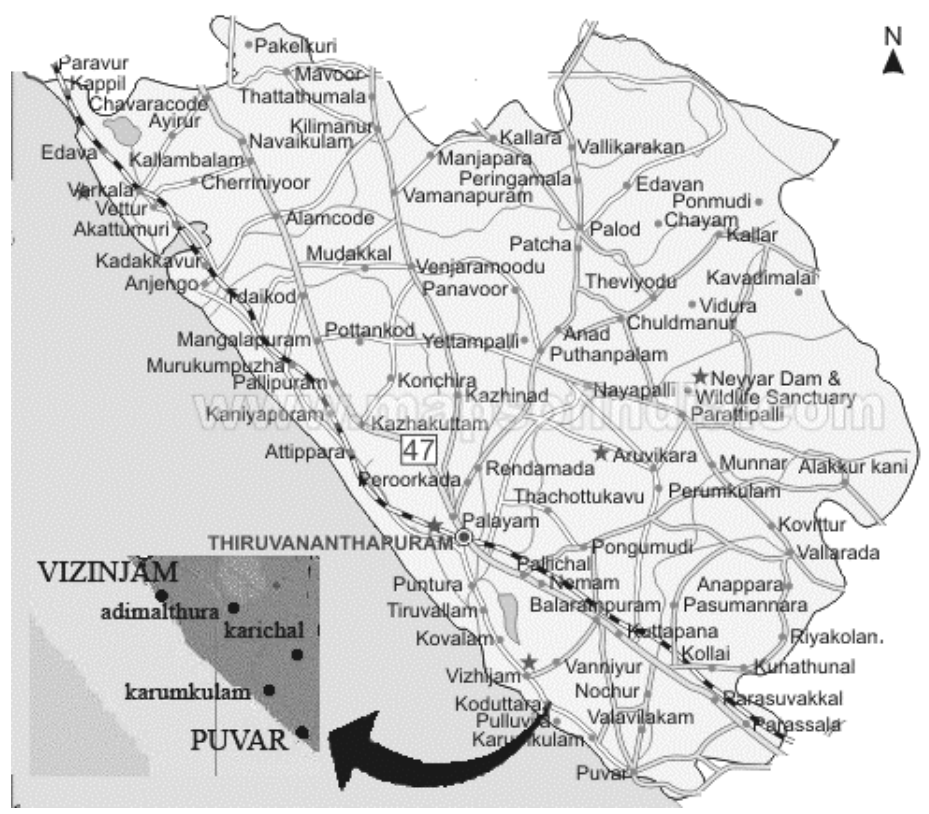

Figure 1: $\quad$ Study region.

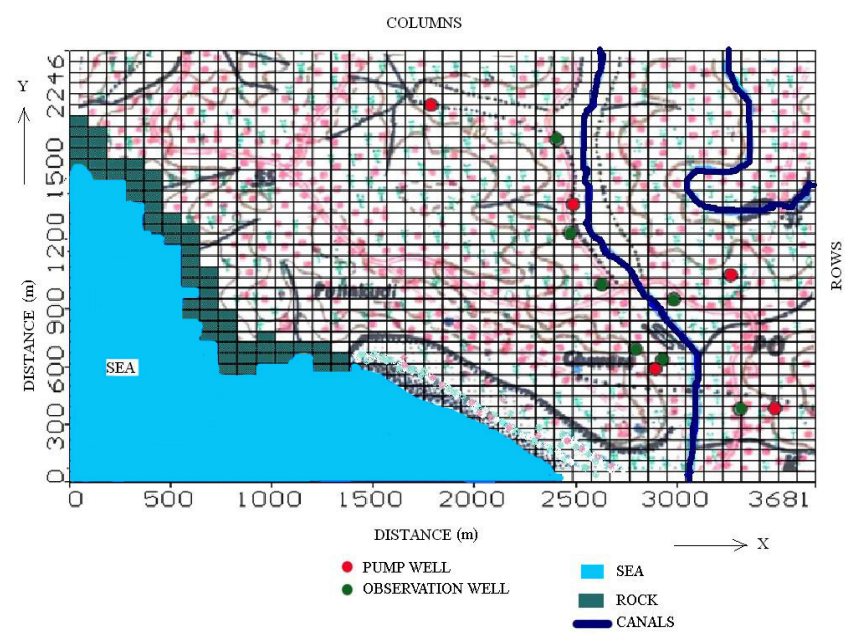

Figure 2: Discretisation of the study region in the XY direction. 


\section{Idealization of the field problem}

\subsection{Spatial discretisation}

To simulate the groundwater interaction in the region a finite-difference model grid was constructed. The grid consists of 40 columns and 40 rows. The area was conceptualized as a five layer system. The five layer system was decided based on the information obtained from a bore log of a near by site and the presence of the river as a boundary. The bore log revealed that the stratum beneath the study area consisted of four layers with respect to the variation in the stratum. The river boundary was considered as a separate layer and thus the area was conceptualized as a five layer system. Layer 1 and Layer 2 as Upper Aquiclude while Layer3 as Unconfined aquifer and Layer 4 as Lower Aquiclude. The Confined aquifer is represented as Layer 5. This gives an idea of horizontal advancement of salinity intrusion in each layer.

To get a precise picture of vertical advancement of intrusion, unit width in Ydirection is assumed and the domain is thus reduced to a two dimensional domain. To simulate the seawater intrusion along vertical sections, a finitedifference model grid was constructed with 1row (representing unit width), 40 columns and 5 layers.

\subsection{Boundary conditions}

To simulate the groundwater heads and seawater intrusion, no-flow boundary cells were assigned to the rock formation on the North West of the study region, which is represented by the green cells in Fig.2. River boundary conditions were applied to the two canals in the study area shown by dark blue lines in Fig2. Constant head and constant concentration cells represent the sea (region in light blue in Fig.2) with head value set to 0 and constant salt concentration set to $35000 \mathrm{mg} /$ lit. Recharge from rainfall infiltration is calculated using the rainfall infiltration factor and was assigned to Layer 1. The strength of source or sink $\left(q_{s}^{\prime}\right)$ in (1) is the term that represents the recharge value. Recharge from rainfall is given by

$$
\mathrm{R}=\mathrm{f} \times \mathrm{A} \times \text { Normal rainfall in monsoon season }
$$

where $\mathrm{R}=$ Recharge from rainfall

$\mathrm{f}=$ rainfall infiltration

$\mathrm{A}=$ area of computation for recharge.

The rainfall infiltration factor for laterite soil recommended by the groundwater resource estimation committee is 0.07 . Since the recharge changes over period of time the entire period of simulation was divided into 18 stress periods so that recharge is constant for a given stress period.

To simulate the seawater intrusion along the vertical direction, seawater hydrostatic conditions were applied to the left boundary (boundary near to sea) with a constant concentration of $35000 \mathrm{mg} / \mathrm{lit}$. Constant freshwater heads were assigned to the cells along the sea boundary using a head value of $0 \mathrm{~m}$. Constant 
concentration of $0 \mathrm{mg} / \mathrm{lit}$ was assigned along the land boundary. Five vertical sections were considered so that each vertical section is across one pumping well out of the five wells chosen.

\subsection{Modeling approach}

Seven observation wells located near to the pumping wells were selected in the study region and water level data was collected for a period of 180 days from April to September. The pumping wells are shown in red dots and observation wells are shown in green dots in Fig.2. The model was calibrated in steady state condition by using water level data from these observation wells. A number of trial runs were made by varying the hydraulic conductivity values of the layers until the differences between the computed and observed values were minimum. The results thus obtained from steady state simulation were used as initial condition and the model was calibrated in transient condition. The calibrated model under transient condition was then used to predict the water levels in the observation wells for a period of one year.

The seawater intrusion in the horizontal direction (X-direction) was simulated for the three dimensional domain using the hydraulic conductivity and storage values obtained from transient state. Calibration was achieved by adjusting the dispersion coefficient for the model within a reasonable range until the values indicating the position of the saltwater interface matched with those values observed in the field. To simulate the seawater intrusion along vertical sections, sections were taken along the three pumping wells - Karichal, Pollinkudi, and Adimalathura.

\section{$7 \quad$ Results and discussions}

\subsection{Simulation of groundwater head}

The model was calibrated in steady state to estimate model parameters like conductivity and specific yield. Simulation runs were performed in steady state for the model to calculate groundwater heads in the region for a period of 180 days. The steady state head values for different wells were obtained and when these heads were compared with the observed heads it yielded a correlation coefficient of 0.75 . The model was also calibrated and run in transient state to yield model parameters and transient heads.

\section{Hydraulic Conductivity}

Upper aquiclude

Unconfined aquifer

Lower aquiclude

Confined aquiclude

$\begin{array}{ll} & -\quad 0.004 \mathrm{~m} / \text { day } \\ - & 25 \mathrm{~m} / \text { day } \\ & -\quad 0.002 \mathrm{~m} / \text { day } \\ - & 8.5 \mathrm{~m} / \text { day } \\ & \\ - & 1 \times 10^{-5} \\ - & 0.005 \\ & -\quad 0.0006\end{array}$

Specific Yield

Aquiclude

Unconfined aquifer

Confined aquifer

- $\quad 0.0006$ 


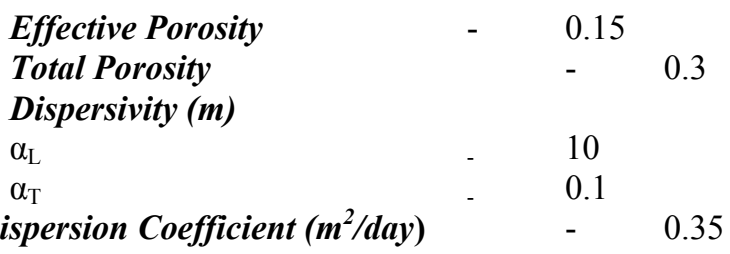

\subsection{Simulation of seawater intrusion}

The seawater intrusion front in the region in the horizontal direction for the five layers is simulated. For the first three layers intrusion is not seen up to $1400 \mathrm{~m}$ (in $\mathrm{X}$ direction) from the origin of model domain. This can be attributed to the fact that no-flow boundary condition is applied in these layers. From 1400m the intrusion is seen in the three layers. For the first two layers, seawater intrusion front is $250 \mathrm{~m}$ from the coast and for the third layer the intrusion front is $500 \mathrm{~m}$ from the coast. For the fourth and fifth layer we have not applied no- flow boundary condition since it is assumed that the depth of rock does not extend to the depth where these layers are present. Hence unlike the first three layers wherein there was no intrusion due to the presence of rock up to $1400 \mathrm{~m}$, it is seen that there is advancement of the seawater intrusion front in these layers even within this distance of $1400 \mathrm{~m}$. For these two layers up to a distance of $1400 \mathrm{~m}$ from the origin of the model domain the intrusion front is $200 \mathrm{~m}$ and after $1400 \mathrm{~m}$ the intrusion front is $400 \mathrm{~m}$ from the coast. A sample result obtained for layer 1 and layer 5 are shown in Figures 3 and 4.

The seawater intrusion front in the vertical direction along the three pumping wells Karichal, Pollinkodi and Adimalathura is simulated.

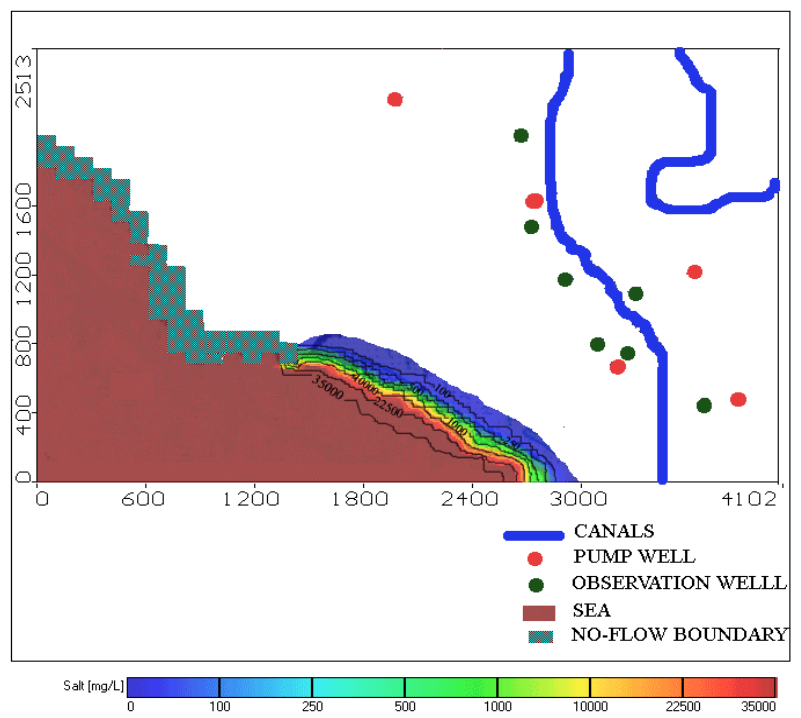

Figure 3: $\quad$ Extent of seawater intrusion in the horizontal direction for layer 1. 


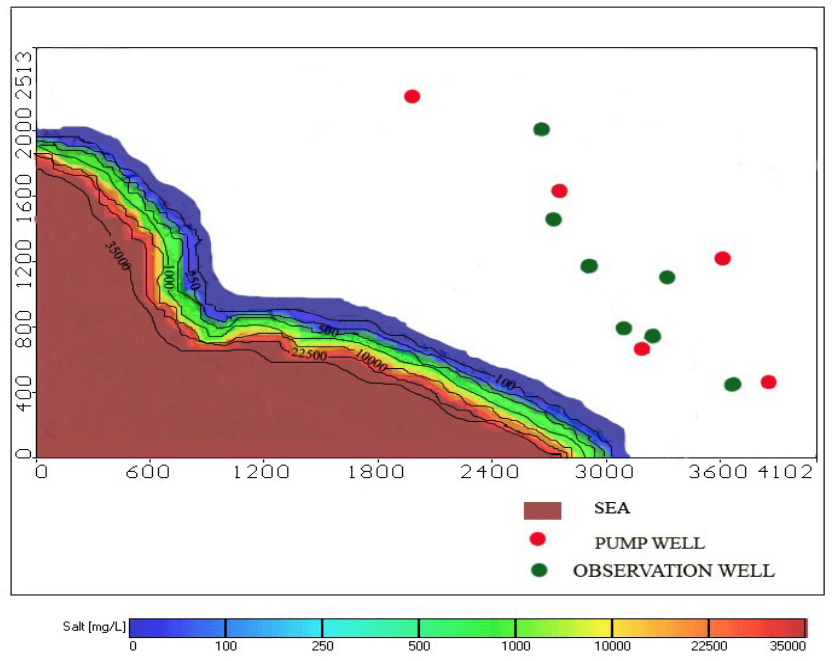

Figure 4: $\quad$ Extent of seawater intrusion in the horizontal direction for layer 4 and layer 5.

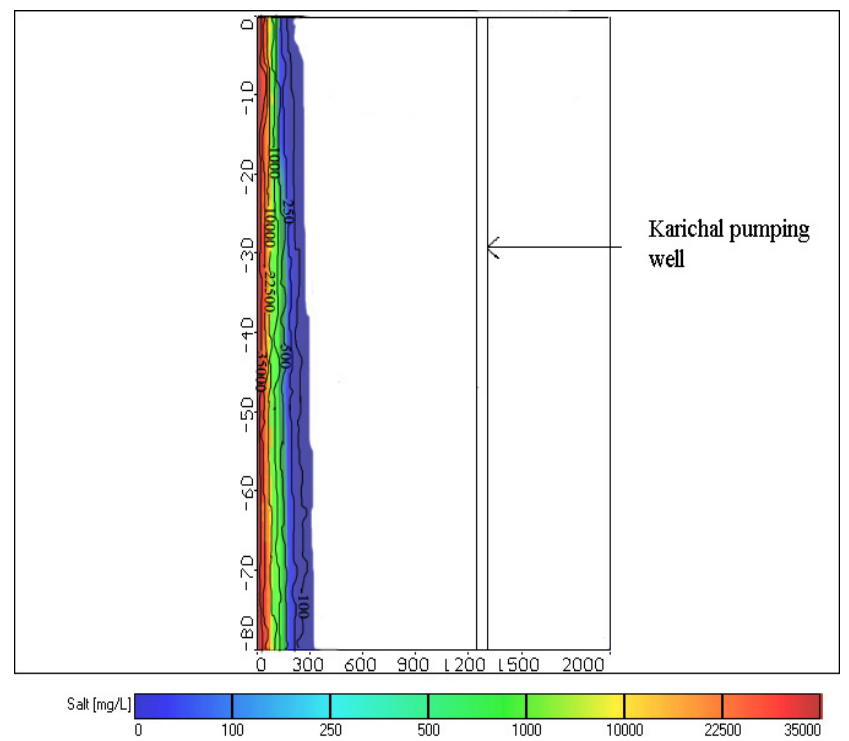

Figure 5: Extent of seawater intrusion for a vertical section along the Karichal pump well.

For the section along the Karichal pumping well the toe of saltwater intrusion front lies $240 \mathrm{~m}$ from the coastal line. For the section along the Pollinkodi pumping well the toe of saltwater intrusion front lies $450 \mathrm{~m}$ from the coastal line. In this well the effect of seawater intrusion is seen in a depth range of $20-60 \mathrm{~m}$ 
below ground surface. For the section along the Adimalathura pumping well the toe of saltwater intrusion front lies $240 \mathrm{~m}$ from the coastal line. The extent of seawater intrusion along the Karichal pump well and Pollinkodi pumping well are shown in Fig. 5 and Fig. 6 respectively.

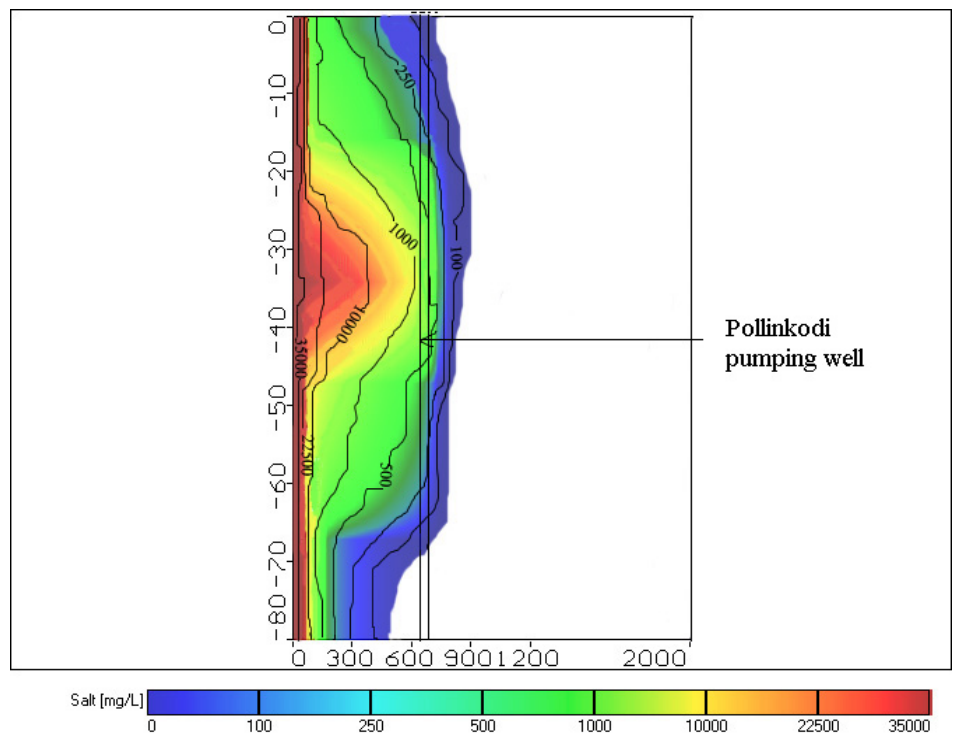

Figure 6: Extent of seawater intrusion for a vertical section along the Pollinkodi pump well.

\section{Conclusion}

The model was calibrated in steady state to estimate model parameters like conductivity and specific yield. Simulation runs were performed for the model to calculate groundwater heads in the region for a period of 180 days. The model was then applied to simulate seawater intrusion in horizontal direction. From the simulation it is seen that for a depth of $40 \mathrm{~m}$ from ground surface intrusion is not seen up to $1400 \mathrm{~m}$ (in $\mathrm{X}$ direction) from the origin of the model domain. This can be attributed to the fact that no-flow boundary condition is applied in these layers. From $40 \mathrm{~m}$ to $80 \mathrm{~m}$, there is advancement of the seawater intrusion front even within this distance of $1400 \mathrm{~m}$. This may be due to the fact that the depth of rock does not extend to the depth where these layers are present and hence noflow boundary condition is not applied to these two layers. As a result, in this depth range (40-80m) up to a distance of $1400 \mathrm{~m}$ measured from the origin of the model domain, the intrusion front has advanced to a distance of $200 \mathrm{~m}$ from the coast.

From the simulation it is seen that from a distance of $1400 \mathrm{~m}$ measured from the origin of model domain, seawater intrusion front is observed in all the five layers. From ground surface up to a depth of $28 \mathrm{~m}$ the intrusion front has 
advanced to a distance of $250 \mathrm{~m}$ from the coast. From $28-40 \mathrm{~m}$ depth, the intrusion front seems to have advanced to a distance of $500 \mathrm{~m}$ from the coast. From $40-80 \mathrm{~m}$ depth, the presence of the intrusion front is seen up to a distance of $400 \mathrm{~m}$ in the horizontal direction. Thus the advancement of seawater intrusion front is at maximum for a depth of $28-40 \mathrm{~m}$ from the ground surface. The extent of seawater intrusion is less up to a depth of $28 \mathrm{~m}$ and this may be due to the recharge from the canals present in the region.

\section{References}

[1] Ghassemi, J., Jakeman, A.J., Jacobson, G. and Howard, K.W.F (1996). "Simulation of Sea Water Intrusion 2D and 3D Models: Naru Island Case Study," Hydrology Journal. Vol.-4(3), pp. 4-22.

[2] Yakirevich, A., Melloul, A., Sorek, S., Shaath, S. and Borisov, V. (1998). "Simulation of Sea Water Intrusion into the Khan Yunis area of the Gaza Strip Coastal aquifer." Hydrogeology Journal Vol.-6,pp.549-559

[3] Guo, W. and Langevin, C.D. (2002). "User's Guide to SEAWAT: A Computer Program for Simulation of Three-Dimensional Variable-Density Ground-Water Flow"

[4] Liu, W.C., Hsu, M.H., Wu, C.R., Wang, C.F. and Kuo, A.Y. (2004) "Modeling Salt Water Intrusion in Tanshui River Estuarine System-CaseStudy Contrasting Now and Then." Journal of Hydraulic Engineering, Vol.130(9), pp.849-859.

[5] Paritsis, S.N. (2005)."Simulation of Seawater Intrusion into The Tymbaki Aquifer, South Central Crete, Greece"

[6] Langevin, C.D and Weixing, G. (2006)."MODFLOW/MT3DMS- Based Simulation of Variable-Density Ground Water Flow and Transport." Ground Water. Vol-44(3), pp. 339-351. 